\title{
Maternal age and the incidence of aneuploidy in first-cleavage mouse embryos $\dagger$
}

\author{
I. Maudlin* and Lynn R. Fraser $\dagger$ \\ Clinical Research Centre, Watford Road, Harrow, Middlesex HAI 3UJ, U.K.
}

\begin{abstract}
Summary. Eggs obtained from young virgin and aged parous female mice were fertilized in vitro to compare the incidence of aneuploidy in the resulting first-cleavage embryos. There was a significantly higher incidence of aneuploidy in the aged group $(7.5 \%$ versus $3.3 \%$ ) and this was due solely to a higher proportion of trisomic female chromosome complements; there was no difference in the incidence of monosomics. These results thus suggest that non-disjunction occurs more frequently in eggs from older females, leading to the production of aneuploid embryos.
\end{abstract}

\section{Introduction}

The relationship between maternal age and the incidence of human trisomy is now well established from studies of abortuses (Alberman, Creasy, Elliott \& Spicer, 1976). Many attempts have been made with the laboratory mouse to verify experimentally this relationship between age and aneuploidy, but results have proved inconclusive. The task is made more difficult because the proportion of fetuses which are aneuploid decreases as pregnancy proceeds (Ford \& Evans, 1973); Goodlin (1965) was unable to find any aneuploids among 756 newborn mice from aged mothers. Yamamoto, Endo \& Watanabe (1973) compared 10.5-day-old fetuses from aged and young females and found 10 aneuploids among 156 embryos $(6.5 \%)$ in the aged group, significantly more than the 2 among 149 controls $(1.3 \%)$, although 6 of those in the aged group were mosaics which generally arise after fertilization by non-disjunction during the early cleavage stages (Vickers, 1969). If the mosaics are excluded, there is no significant difference in the incidence of aneuploidy.

In addition to such direct observations, much indirect evidence has been presented to relate maternal age and the incidence of aneuploidy in the mouse. Henderson \& Edwards (1968) reported that oocyte chiasma frequency declined with maternal age in the mouse, this decline being correlated with an increase in univalent formation. Although this observation has since been confirmed by Luthardt, Palmer \& Yu (1973), Polani \& Jagiello (1976) found that the observed frequency of univalents at first meiotic metaphase did not correspond to the numbers of chromosomal anomalies at the second meiotic division and they concluded that the data could not account for an age effect. Studies based on chiasma frequency and observation of univalents may therefore produce overestimates of the incidence of embryonic aneuploidy. Martin, Dill \& Miller (1976) have reported an increased incidence in hyperploidy $(n+1)$ in oocytes at metaphase of meiosis II recovered from old CBA females compared with those from young animals, but again this does not necessarily indicate the increased production of aneuploid embryos. Even if non-disjunction occurs in some oocytes, they may not be fertilized. Apart from these cytogenetic observations, there is some genetic evidence to support a reduction in chiasma frequency with age (Fisher, 1949; Bodmer, 1961; Reid \& Parsons, 1963), although a recent study in the mouse has failed to confirm this (Wallace, MacSwiney \& Edwards, 1976).

A study of preimplantation stages avoids the problem of post-implantation losses and should give more useful data on the primary incidence of aneuploidy. Gosden (1973) found 4 aneuploids in a group of 58 morulae and blastocysts $(6.9 \%)$ from aged females compared with the single trisomic

* Present address: Nigerian Institute for Trypanosomiasis Research, PMB 2077, Kaduna, Nigeria.

$\dagger$ Present address and address for reprints: Department of Human Biology, Basic Medical Sciences Group, Chelsea College, Manresa Road, London SW3 6LX, U.K. 
among 47 embryos of similar stages $(2 \cdot 1 \%)$ taken from young females. This result suggests an agerelated effect but is limited by the small numbers of embryos analysed.

An analysis of the chromosome complements of 1-cell mouse embryos provides a better method of determining the effect of maternal age on the primary incidence of embryonic aneuploidy. In such embryos, the egg-derived chromosomes can be distinguished from the sperm complement because of their differential condensation (McGaughey \& Chang, 1971; Donahue, 1972). By using males with a T6 marker chromosome, we have shown that it is possible to distinguish male and female chromosome complements in nearly all first-cleavage embryos fertilized in vitro (Maudlin \& Fraser, 1977); sperm penetration in vitro occurs within a relatively short time so that the embryos represent a fairly synchronous population, unlike ones recovered from different females following natural mating. Furthermore, the proportion of such embryos giving preparations which can be scored for aneuploidy is high ( $>80 \%$ ). In the present study, we have used chromosomal analysis of first-cleavage mouse embryos to compare the incidence of aneuploidy in eggs obtained from aged parous and young virgin TO females and fertilized in vitro by spermatozoa obtained from young TO males.

\section{Materials and Methods}

Young (2-4-month-old) virgin and aged (8-10-month-old) parous TO females were used; the old females had reached the age when reproductive efficiency has begun to decline in TO mice (C. M. Hetherington, personal communication). Vasectomized TO males were introduced into the cages of the aged females every 2 weeks to maintain cyclicity until the females were used. The vaginas of the females were examined (Champlin, Dorr \& Gates, 1973) weekly to verify that oestrous cycles were occurring; there was no indication that the mice were becoming anoestrous. All females were induced to superovulate with 7.5 i.u. PMSG (Gestyl; Organon) and 5.0 i.u. hCG (Pregnyl; Organon), and were killed $13 \mathrm{~h}$ after the hCG injection for recovery of unfertilized eggs. Epididymal TO sperm suspensions were prepared (Fraser \& Drury, 1975) from 2-4-month-old males, preincubated for $2 \mathrm{~h}$ to ensure capacitation (Fraser \& Drury, 1976), diluted to $2 \times 10^{6}$ spermatozoa/ml, and eggs were added. Incubation and processing of 1-cell embryos for chromosome analysis were carried out as described previously (Maudlin \& Fraser, 1977). In both groups the fertilization level, as determined by the presence of second polar bodies, was approximately $80 \%$.

\section{Results}

Table 1 shows the incidence of aneuploidy in the two groups of embryos from aged and young females. The data have been partitioned into female-derived aneuploidy, male-derived aneuploidy and embryonic (male + female/2) aneuploidy. Because of the differential condensation of female

Table 1. The incidence of aneuploidy in 1-cell embryos of the TO mouse strain derived from the eggs from aged parous and young virgin females and fertilized in vitro by TO spermatozoa

\begin{tabular}{|c|c|c|c|c|c|c|}
\hline & \multicolumn{2}{|c|}{ Monosomic } & \multicolumn{2}{|c|}{ Trisomic } & \multicolumn{2}{|c|}{ Total aneuploids $\dagger$} \\
\hline & Aged & Young & Aged & Young & Aged & Young \\
\hline $\begin{array}{l}\text { Female- } \\
\text { derived complement }\end{array}$ & $9(2 \cdot 4 \%)$ & $7(1.6 \%)$ & $* 12(3.2 \%)$ & $4(0.9 \%)$ & $* 21 / 375(5.6 \%)$ & $11 / 434(2.5 \%)$ \\
\hline $\begin{array}{l}\text { Male-derived } \\
\text { complement }\end{array}$ & $0(0 \%)$ & $2(0.5 \%)$ & $4(1 \cdot 4 \%)$ & $1(0.2 \%)$ & $4 / 293(1.4 \%)$ & $3 / 419(0.7 \%)$ \\
\hline Embryonic incidence & $9(2.7 \%)$ & $9(2 \cdot 1 \%)$ & $* * 16(4.8 \%)$ & $5(1.2 \%)$ & $* 25 / 334(7.5 \%)$ & $14 / 427(3.3 \%)$ \\
\hline
\end{tabular}

Probabilities calculated by Fisher's Exact test compared with the value for young females; $P=0.05-0 \cdot 01 ; * * P=$ $0.01-0.001$.

$\dagger$ No. of aneuploid embryos/total embryos scored. 
and male complements for the first cleavage division, the male chromosomes are sometimes still in late prophase and do not yield confident counts; therefore the number of confident female counts exceeds the male counts. There was a significantly greater incidence of aneuploidy in the embryos from the aged females $(7.5 \%)$ compared with the control group $(3.3 \% ; P=0.012)$. Separate analysis of the male-derived and female-derived frequencies showed that this embryonic difference was due solely to differences between the female complements of the two groups. Moreover, analysis of the female data showed that there was no significant difference between groups in the incidence of monosomy $(P=0.457)$; rather, the difference lay in the incidence of trisomy $(P=0.023)$.

\section{Discussion}

The present work has demonstrated a significant increase in the incidence of aneuploidy in 1-cell mouse embryos from aged parous females compared with that observed in embryos from young virgin females, both groups being fertilized in vitro. Moreover, this difference was due to an excess of trisomics which, unlike monosomics, are less likely to be artefactual. This result is of particular interest because, in man, few autosomal monosomic abortuses have been found although trisomic spontaneous abortuses are common (Polani, 1970). It has been assumed that monosomics and trisomics are produced with approximately equal frequencies at fertilization, but that post-implantation selection due to lower viability of monosomics results in the observed differences later in development (Ford \& Evans, 1973).

In none of our other studies on first-cleavage mouse embryos have we detected any significant difference in the incidence of either monosomy or trisomy between embryos fertilized in vitro and in vivo, indicating that the system itself does not generate such anomalies (Maudlin \& Fraser, 1977, 1978; Fraser \& Maudlin, 1978). Furthermore, these data obtained from first-cleavage embryos are consistent with the results of Martin et al. (1976) which indicated a significantly higher incidence of hyperploidy $(n+1)$ in metaphase II oocytes from old CBA females than from young ones; assuming fertilization by haploid spermatozoa and normal completion of meiosis, such oocytes would give rise to trisomic embryos. The former mice were classified, in fact, as 'middle-aged', being 150-240 days old and in the waning part of their reproductive life. In terms of reproductive potential, therefore, those CBA females were similar to the old TO females (240-300 days old) used in the present experiments.

Our results are consistent with the idea that the probability of meiotic non-disjunction increases with maternal age, thus leading to an increased incidence of aneuploid embryos. In the mouse, our results suggest that there is a preferential production of trisomic, rather than monosomic, embryos.

We thank Dr C. E. Ford for his support and advice.

\section{References}

Alberman, E., Creasy, M., Elliott, M. \& Spicer, C. (1976) Maternal factors associated with fetal chromosomal anomalies in spontaneous abortions. Br.J. Obstet. Gynaec. 83, 621-627.

BODMER, W.F. (1961) Effects of maternal age on the incidence of congenital abnormalities in mouse and man. Nature, Lond. 190, 1134-1135.

Champlin, A.K., Dorr, D.L. \& Gates, A.H. (1973) Determining the stage of the estrous cycle in the mouse by the appearance of the vagina. Biol. Reprod. 8, 491-494.

DonahuE, R.P. (1972) Cytogenetic analysis of the first cleavage division in mouse embryos. Proc. natn. Acad. Sci. U.S.A. 69, 74-77.

FisheR, R.A. (1949) A preliminary linkage test with agouti and undulated mice. Heredity 3, 229241.
Ford, C.E. \& Evans, E.P. (1973) Non-expression of genome unbalance in haplophase and early diplophase of the mouse and incidence of karyotype abnormality in post-implantation embryos. In Chromosomal Errors in Relation to Reproductive Failure, pp. 271-285. Eds A. Boué \& C. Thibault. INSERM, Paris.

FraSER, L.R. \& DRURY, L.M. (1975) The relationship between sperm concentration and fertilization in vitro of mouse eggs. Biol. Reprods. 13. 513-518.

Fraser, L.R. \& DRURY, L.M. (1976) Mouse sperm genotype and the rate of egg penetration in vitro. J.exp. Zool. 197, 13-19.

Fraser, L.R. \& MAUDlin, I. (1978) Relationship between sperm concentration and the incidence of polyspermy in mouse embryos fertilized in vitro. J. Reprod. Fert. 52, 103-106. 
Goodlin, R.C. (1965) Non-disjunction and maternal age in the mouse. J. Reprod. Fert. 9, 355-356.

GosDEn, R.G. (1973) Chromosomal anomalies of preimplantation mouse embryos in relation to maternal age. J. Reprod. Fert. 35, 351-354.

Henderson, S.A. \& Edwards, R.G. (1968) Chiasma frequency and maternal age in mammals. Nature, Lond. 218, 22-28.

Luthardi, F.W., Palmer, C.G. \& Yu, P.L. (1973) Chiasma and univalent frequencies in aging female mice. Cytogenet. Cell Genet. 12, 68-79.

Martin, R.H., Dill, F.J. \& Miller, J.R. (1976) Nondisjunction in aging female mice. Cytogenet. Cell Genet. 17, 150-160.

Maudlin, I. \& Fraser, L.R. (1977) The effect of PMSG dose on the incidence of chromosomal anomalies in mouse embryos fertilized in vitro. $J$. Reprod. Fert. 50, 275-280.

Maudlin, I. \& Fraser, L.R. (1978) The effect of sperm and egg genotype on the incidence of chromosomal anomalies in mouse embryos fertilized in vitro. $J$. Reprod. Fert.52, 107-112.
McGaughey, R.W. \& Chang, M.C. (1971) Chromosomes at prometaphase and metaphase of the first cleavage in mouse and hamster eggs. J. exp. Zool. 177, 31-40.

Polani, P.E. (1970) The incidence of chromosomal malformations. Proc. R. Soc. Med. 63, 14-16.

Polani, P.E. \& Jagiello, G.M. (1976) Chiasmata, meiotic univalents, and age in relation to aneuploid imbalance in mice. Cytogenet. Cell Genet. 16, 505529.

ReID, D.H. \& PARsons, P.A. (1963) Sex of parent and variation of recombination with age in the mouse. Heredity 18, 107-108.

Vickers, A.D. (1969) Delayed fertilization and chromosomal anomalies in mouse embryos. J. Reprod. Fert. 20, 69-76.

Wallace, M.E., MacSwiney, F.J. \& Edwards, R.G. (1976) Parental age and recombination frequency in the house mouse. Genet. Res. 28, 241-251.

Yamamoto, M., Endo, A. \& Watanabe, G. (1973) Maternal age dependence of chromosome anomalies. Nature, New Biol. 241, 141-142.

Received 25 April 1978 